\title{
SHEARING OF SHEET METAL INSIDE THE TOOL WITH THE INTERNAL HEATING CUTTING PUNCH
}

\author{
Ján MORAVEC
}

University of Žilina, Faculty of Mechanical Engineering, Department of Technological Engineering, Žilina, Slovak Republic, EU, jan.moravec@fstroj.uniza.sk

https://doi.org/10.37904/metal.2019.682

\begin{abstract}
This paper describes issues related to the process of cutting with a punch with internal heating. The theoretical part explains the effects related to thermal expansion, conduction and transfer of heat in the body of punches. The experimental part refers to the design of a tool with an internally heated punch. Experimental results are summarised and the process is analysed in the discussion.
\end{abstract}

Keywords: Metal sheet, internal heating, cutting, cutting tool, forming

\section{INTRODUCTION}

Forming technologies have long used various ways and methods based primarily on physical knowledge. For a longer time, the method has been used of deep drawing using heating the active parts of drawing tools. The first person to describe this method was Romanovskij, V.P. (1958) [1]. In 1965, Srp, K. et al. published this solution [2]. This method is also presented by Čabelka, J. et al. (1967) [3], Blaščík, F. et al. (1988) [4] and Bača, $J$. (1988) [5]. This paper originated on the basis of the above information. We will discuss the possibility of using internal heating in metal sheet cutting using a cutting machine. In the past we have already published a paper on the propagation of heat in the cut zone, in which we dealt with this issue - Moravec, J. (2000) [6].

\section{THEORETICAL PART}

If a cylindrical cutting punch is considered a rod clamped at one end, then a first approximation can read as follows: rods, when heated, expand especially in length. When heating, the amplitudes of oscillating molecules increase and the molecules fill a larger space. Therefore, solids stretch in all directions. A cylinder-shaped cutting punch can be considered the surface area $S_{1}$, which is the area prior to a change in temperature. When performing calculations, we can understand surface expansion as linear expansion in two directions/dimensions (see Figure 1).

The variables are as follows: $S_{1}$ - the surface area prior to temperature change, $S_{2}$ - the surface area following temperature change, $\Delta S$ - the difference of the surface area $=S_{2}-S_{1}, \Delta t$ - the difference of the temperature $=$ $t_{2}-t_{1}$.

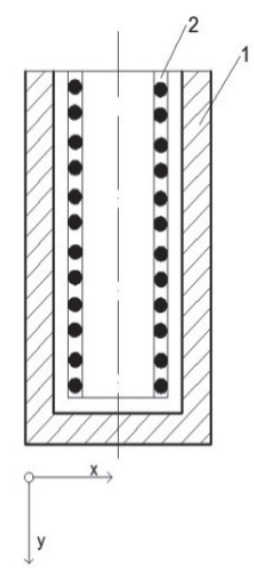

Figure 1 Scheme of a cutting punch with internal heating ( 1 - punch body, 2 - heating body)

The following also applies:

$\Delta S=S_{2}-S_{1}=l_{2}{ }^{2}-l_{1}{ }^{2}=l_{1}{ }^{2}\left(1-\alpha \Delta t^{2}\right)-l_{1}{ }^{2}=l_{1}{ }^{2}\left[1+2 \alpha \Delta t+\alpha^{2}(\Delta t)^{2}\right]-l_{1}{ }^{2}$ 
Since $\alpha$ is small, the member with the square number in the equation can be neglected. Then, the following will apply:

$\Delta S=I_{2}^{2}(1+2 \alpha \Delta t)-I_{1}^{2}=I_{1}^{2} \cdot 2 \alpha \Delta t$

and also:

$\Delta S=S_{1} \cdot 2 \alpha \Delta t$

as well as:

$S_{2}=S_{1}+\Delta S=S_{1}+S_{1} \cdot 2 \alpha \Delta t^{2}$

and finally:

$S_{2}=S_{1}\left(1+2 \cdot \alpha \Delta t^{2}\right)$

where parameters $S$ is area $\left(\mathrm{mm}^{2}\right), /$ is length of the heated body $(\mathrm{mm}), t$ is temperature $\left({ }^{\circ} \mathrm{C}\right)[7]$. The coefficient $\alpha$ depends on temperature to a very limited extend only. Within the range 0 to $100{ }^{\circ} \mathrm{C}$, the values apply as given in physical tables, and with sufficient accuracy.

\section{EXPERIMENTAL PART}

A cavity is formed inside the cutting punch body. A heating body is placed into the cavity. The heating body heats the face of the cutting punch. It was necessary to find out what parameters correspond to the required temperature. A $40 \mathrm{~W}$ tiny heating body (device) from a micro-solder proved to be suitable for experimental work. As shown in Figure 2, we connected the assembly to a $230 \mathrm{~V}$ source, which ensured heating of the active part of the cutting punch. Figure 3 shows a view of the experimental workplace of temperature sensing. The ambient temperature was $26^{\circ} \mathrm{C}$. We found out the following: at $U=116 \mathrm{~V}$, and after 25 minutes, we achieved the temperature of $97^{\circ} \mathrm{C}$, and after 40 minutes the temperature increased to $112{ }^{\circ} \mathrm{C}$ - the value that had to be obtained (to be more precise - we needed to achieve temperature between 100 and $110{ }^{\circ} \mathrm{C}$ ). The real temperature in experimental conditions varied between 108 and $113^{\circ} \mathrm{C}$. We chose this temperature to avoid initiation of phase transformations. The voltage $U_{\text {term }}=4.435 \mathrm{mV} \rightarrow$ $t=110^{\circ} \mathrm{C}, U_{\text {term }}=4.280 \mathrm{mV} \rightarrow t=105.7^{\circ} \mathrm{C}, U_{\text {term }}=4.404 \mathrm{mV} \rightarrow$ $t=109^{\circ} \mathrm{C}$. The final values were as follows: $U=116 \mathrm{~V}$, current

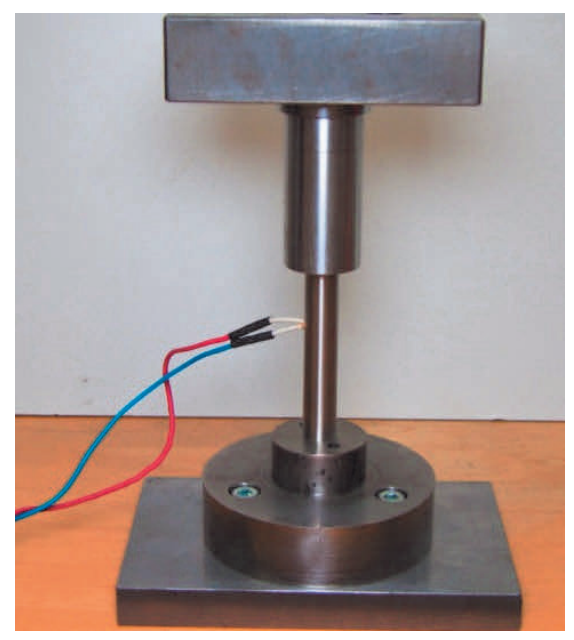

Figure 2 Assembly of the experimental cutting tool $I=78 \mathrm{~mA}, U_{\text {term }}=4.404 \mathrm{mV}$.

Prior to heating, the cutting punch diameter was $15.91 \mathrm{~mm}$, and after heating it reached $15.922 \mathrm{~mm}$, which was measured directly and does not differentiate significantly from the calculated value. This laboratory verification was followed by incorporation of the modified cutting punch with internal heating into the cutting tool assembly. Since it is an open tool without any cutting punch guidance, we had to precisely adjust the tool and consistently clamp it on the press. Figure 4 shows the experimental cutting tool and its clamping on the press [8-10].

The presented tool was clamped on a LESP 63 press, and used to cut 1-mm metal sheet. The metal sheet was made of conventional STN 411321 material, with the composition of $0.10 \% \mathrm{C}, 0.45 \% \mathrm{Mn}, 0.035 \% . P$, $0.035 \% \mathrm{~S}$. The other values included $R_{m}=420 \mathrm{MPa}, R_{e}=235 \mathrm{MPa}, A=26 \%$. The number of blanks was chosen in thousands of pieces. The cutting punch was heated to $108^{\circ} \mathrm{C}\left( \pm 5^{\circ}\right)$. From this perspective, we can 
assess the cutting process with heating as stable. Attention was focused on the effect of heating during the cutting process.

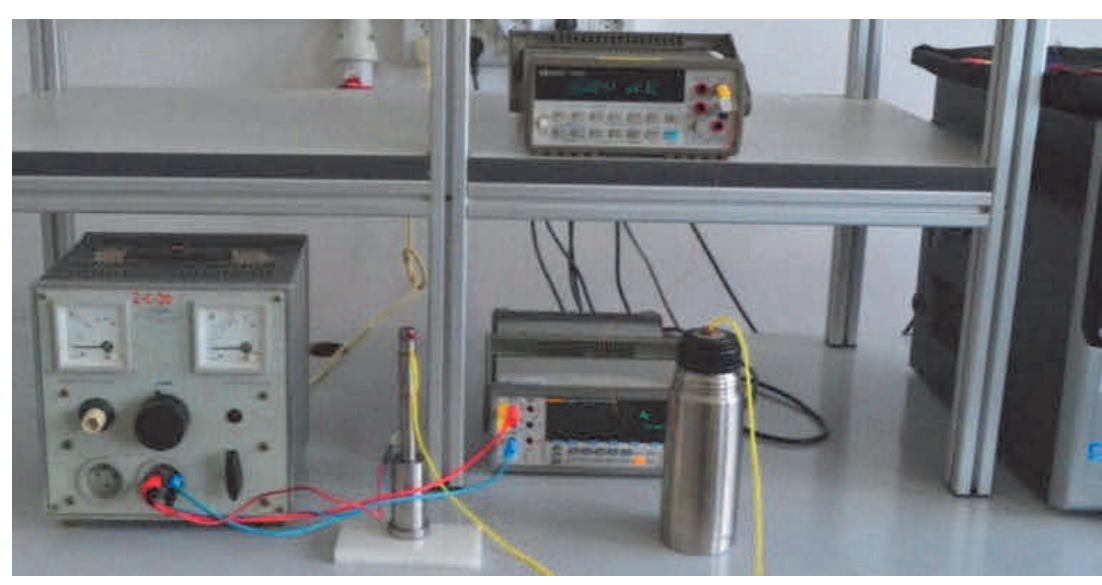

Figure 3 Experimental workplace

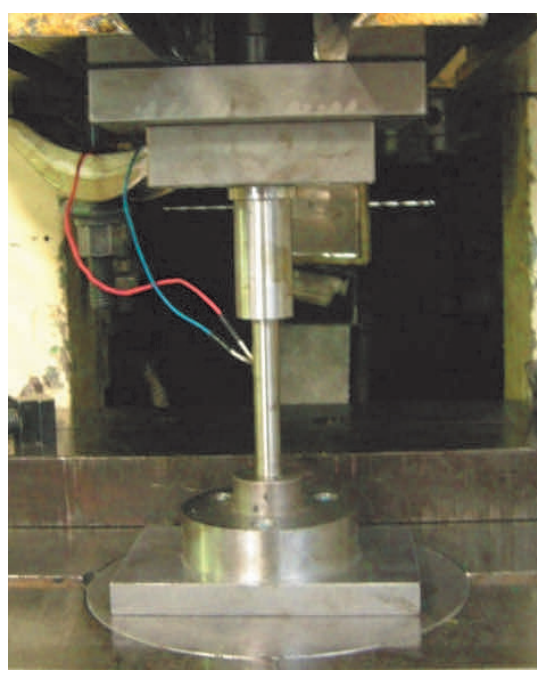

Figure 4 Workplace for cutting

\subsection{Technological aspect}

Using a heated cutting punch, we identified some factors in experimental work that are instrumental in deeper understanding of the above issues. The condition is that heating does not replace the forming tool sharpening, alignment or repair, but only helps prolong the phase of economic wear (see Figure 5). The size of the production batch is of significant influence in the manufacture of blanks (see Figure 6).

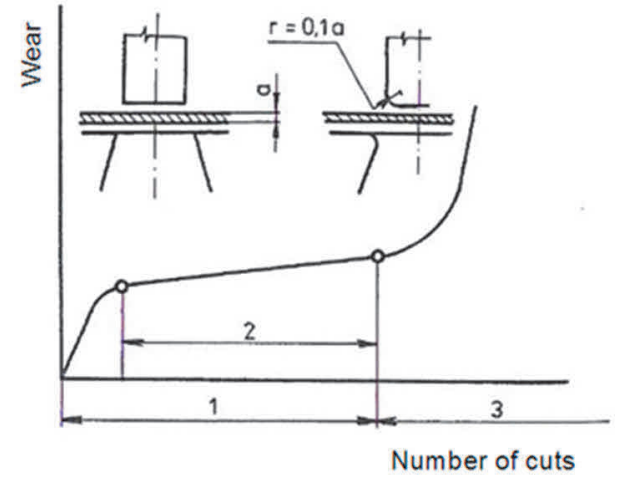

Figure 5 Criterion of the cutting edge wear (1 - sharp tool, 2 - economic wear, 3 - supercritical wear)

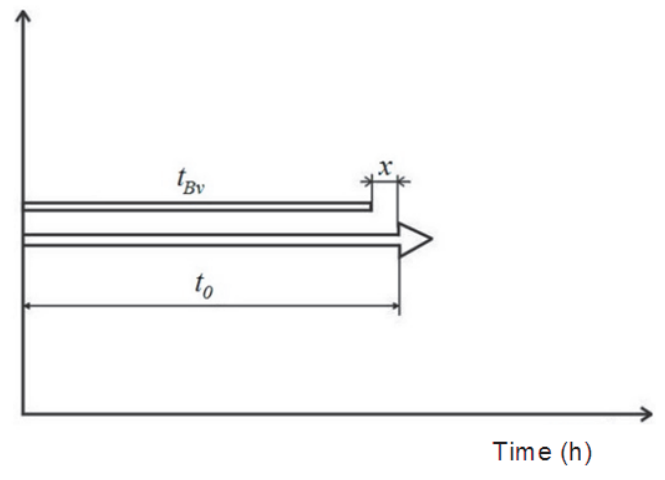

Figure 6 Optimum distribution of continuous production time and tool operation time

Figure 6 shows the optimum distribution of the continuous blank production time and the quality tool operation. The difference $x$ enables re-sharpening and re-aligning of the tool in this section of time value difference. Therefore, it is important to determine the optimum size of the production batch, whereas it should apply that during the time of manufacturing a certain batch, the tool should ensure the quality of parts manufactured in the given batch: $t_{B v} \leq t_{0}$ (where: $t_{B v}$ is the time for manufacturing a batch with $n$ pieces, $t_{0}=t_{p n}$ the time of quality operation of the tool between two acts of re-sharpening or adjustment).

When applying a heated punch in the process of metal sheet cutting, we have to consider what can be achieved with this solution. The following applies generally to sheet cutting, which is a common operation in 
the preparation of blanks, such as bending or deep drawing: cutting tolerance plays a major role. This tolerance is directly dependent on the thickness and mechanical properties of the material being cut. Cutting gap (CG) is half the cutting tolerance. Optimal CG is an important measure of quality of the cutting tool, and it contributes significantly to the overall quality of the desired result of the cutting process.

The geometry of punches and punching dies includes the shape, dimensions and tolerances of the working parts of the cutting tools. The following applies: the size of the punched hole determines the punch dimensions, and the blank size determines the punching die and punch dimensions. In holepunching operations (openings and blanks), the part of material that falls from the opening (waste) determines the size of the cut-out hole, whereas the size of the punch and punching die is enlarged by the cutting tolerance. The size of a blank resulting from the cutting operation depends on the punching die size, therefore the cutting gap size is on the expense of the cutting punch. The cutting punch size will be smaller by the cutting tolerance value. Hence, it follows that the cutting tolerance is the difference in dimensions of the punching die and the punch in the corresponding point of cross-section. It is the distance of the punch from the punching die after its insertion at any point. The ideal cutting gap is uniform all along the punching die (punch) circumference, and is equal to half

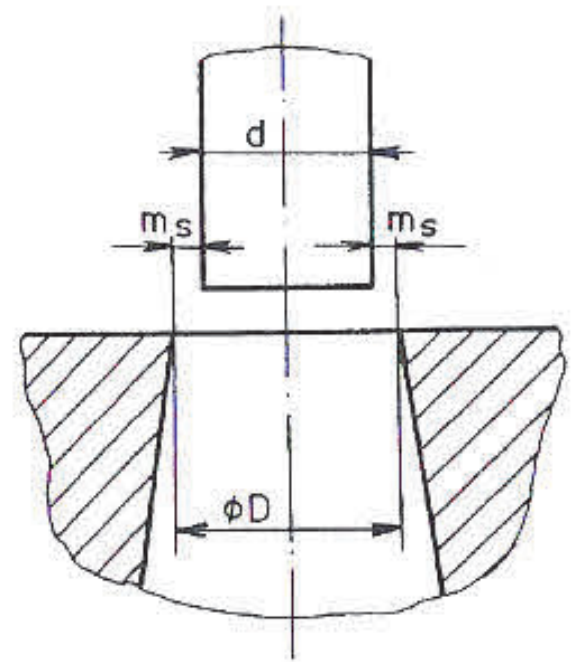

Figure 7 Cutting gap and cutting tolerance the cutting tolerance (see Figure 7) [11-13].

Optimum cutting gap is an important measure of quality of cutting tools. It has a decisive influence on the durability of the cutting edge and the service life of the tool. Its size depends mainly on the thickness and mechanical properties of the material to be cut. An optimum cutting gap is considered the one that is uniform along the entire cut curve and that achieves the required quality of the cutting surface with a minimum exercised force and labour. A reduction in the cutting gap leads to an increase in cutting force as well as labour. Increase in the force is not large, but increase in labour can reach up to $40 \%$.

Since the size of the cutting gap changes during the operation due to the cutting edge wear, new tools are made with minimum acceptable cutting gap. Cutting edges gradually wear out, the cutting gap grows, and when it exceeds the region of economic wear, the forming force increases by $55 \%$. It applies for the upper limit of the economic wear region that the cutting edge radius $R=0.1 \mathrm{a}$, where $a$ is the thickness of the material being cut (see Figure 5). Such wear is followed by a necessary renovation of cutting edges.

It follows from the above considerations that using a heated punch possibly results in quite properly corrected size of the cutting tolerance. As mentioned above, the increase in applied force at reduced cutting gap is small, but the labour increment is significant. This can be easily read in the graph in Figure 5. Therefore, we are dealing with the maximum length of section 2 that represents the economic wear. The amount of labour in this section increases rather gradually, not in leaps. Certainly, there is also a significant impact of the amount of heating of the active part of the cutting tool.

When applying a heated cutting punch, one must consider such a structure as early as in the design stage of the forming tool, with the economic aspect of the process coming to the fore here. According to Figure $\mathbf{8}$, the appropriate cutting tolerance is exceeded at a certain stage of the cutting process. And it is exactly at this moment that a heated cutting punch can be applied so that the acting part of the forming tool gets heated and quite simply corrects the cutting tolerance in order to ensure that the process runs as if with a re- 
adjusted tool and corrected cutting tolerance. Using this solution can be generally recommended in the cases when the cutting tolerance increases to the extent that the blanks feature visible burrs with a height exceeding the permissible level of cut tolerance. The size (dimensions) of cutting punches also plays its role here, since the larger the size, the larger the linear expansion coefficient. Of course, the important in the process is only the direction in the $x$ axis, elongation in the $y$ direction does not affect the cutting process (see Figure 1).
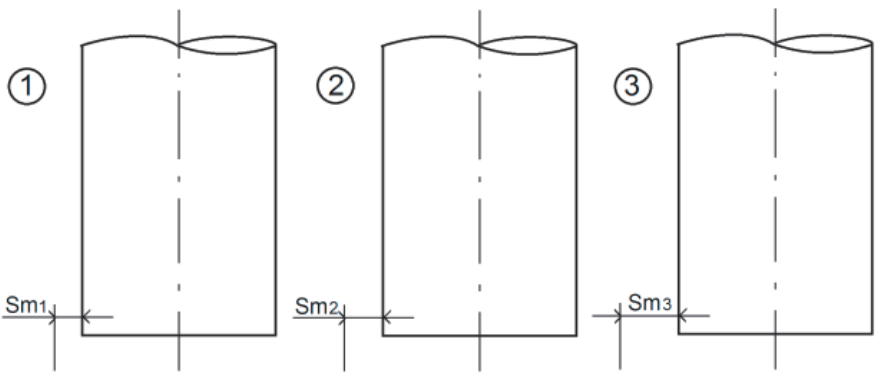

Figure 8 Change in the cutting gap resulting from the cutting punch wear $\left(s_{m 1}<s_{m 2}>s_{m 3}\right)$

\subsection{Quality of cutting surface}

Field tests did not find any significant difference on the cutting surfaces between the quality of the surface being cut traditionally (without any heating), and with the applied heating of the active part. The above facts had been expected, and the assumption was fully confirmed. Surface roughness measurement was carried out using HOMMEL WERKE LV-2-50. The surface roughness was $R_{a}=0.60 \mu \mathrm{m}$. The 850 pieces of cuts were measured and Figure 9 shows the surface roughness of the shear surface of the cut.

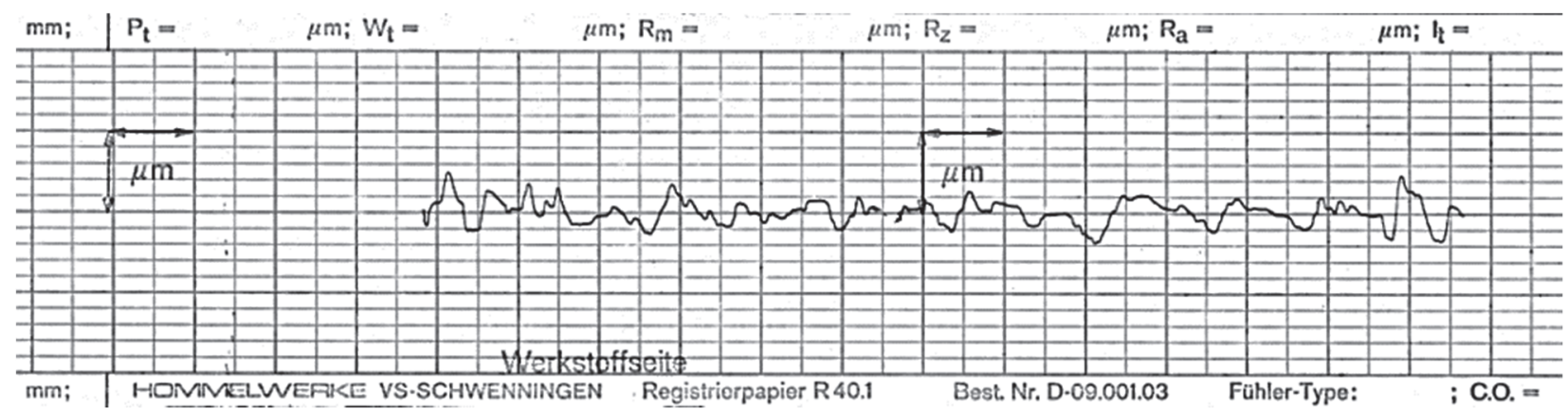

Figure 9 Surface roughness when hot cutting after 850 strokes

\section{CONCLUSION}

This paper describes the issue of applying heating to the cutting process. We presented the theoretical background, construction solution (design) of an experimental tool, and the results of experimental tests. Phase transformation is each qualitative change in the state of the same substance (in particular, steel), which occurs at least in a certain part of the observed system due to changes in conditions (temperature, pressure, electric field, magnetic field). The above processes may after all result in complete disappearance of the initial matrix phase, to be replaced by a new phase. In the case of an active component such cutting punch, this actually becomes disabled since the required hardness is reduced. In thermo-mechanical terms, phase transformations constitute a transition from the state when it is characterised by a higher value of free enthalpy to a state with its lower value. The loss of energy is represented by labour involved in carrying out the contemplated conversion:

$-\Delta G=\left(d A_{\max }\right)_{\text {notvol }}$

where $\Delta G=\Delta H-T \cdot \Delta S,\left(d A_{\max }\right)_{\text {notvol }}$ is the maximum not volumetric labour, $\Delta H$ is the system enthalpy change, $T$ is the temperature $(\mathrm{K}), \Delta S$ is the system enthalpy change [14]. 
This paper adds new knowledge and conclusions to the large sphere of the issue of metal sheet cutting.

\section{REFERENCES}

[1] ROMANOVSKIJ, J. P. Guide for Cold Pressing, (in Czech). 1958 SVTL Praha.

[2] SRP, K., ŘIMAN, J., SRP, B., HRADILIK, B. and SILVA, M. Basics of Pressing (in Czech). 1965 SNTL Praha.

[3] CABELKA, J., PISEK, F., OSINA, V., WEBER, K., ODSTRCIL, B., VETISKA, A., PRIMUS, F., FARLIK, A., DRASTIK, F., KONECNY, F., SKRABAL, E., DIRHAN, J., TEINDL, J. and PARYZEK, J. Mechanical Technology (in Slovak). SAV: Bratislava 1967.

[4] BLASCIK, F., ADAMKA, J., PILARIK, S., ZITNANSKY, M., ZEMAN, K. and POLAK, K. Forming Technology, Casting and Welding (in Slovak). ALFA: Bratislava 1988.

[5] BACA, J. Forming (in Slovak), SVST: Bratislava 2000.

[6] MORAVEC, J. Heat Transfer Zone Shear (in Slovak). Material Engineering. 2000. vol. 7, no. 2, pp. 29-37.

[7] MORAVEC, J. Cutting metal sheet with a punch with internal heating. Communications. 2016. vol. 18, no. 3, pp. 71-77.

[8] MORAVEC, J. Unconventional Methods of Forming Metal (in Slovak), EDIS: University of Zilina, 2011, 135p.

[9] HOSFORD, W. F. and CADDEL, R. M. Metal Forming, Mechanics and Metallurgy. Cambridge University Press, 2011.

[10] JOHNSON, W. and MAMALIS, A. G. Plasticity and Metal Forming. Cambridge, 1998.

[11] MARCINIAK, Z., DUNCAN, J. L. and HU, S. J. Mechanics of Sheet Metal Forming. Butterworth-Heinemann, Jordan Hill: Oxford, 2002, p.221.

[12] BOLJANOVIC, V. Sheet Metal Forming Processes and die Design. $1^{\text {st }}$ ed. New York: Industrial Press. 2005. p. 215.

[13] PEARCE, R. Sheet Metal Forming. $1^{\text {st }}$ ed. Adam Hilger. 1991. p. 275.

[14] BELAN, J. Theory of Phase transformations. Zilina: EDIS University Press, University of Zilina, 2015. 